\title{
Assessment of the impact of the northern territories of oil and gas facilities on the environment
}

\author{
Larisa Gilyova ${ }^{1, *}$, Marina Podkovyrova ${ }^{1}$ \\ ${ }^{1}$ Industrial University of Tyumen, Volodarsky Street, 56, 625000, Tyumen, Russia
}

\begin{abstract}
The article highlights the problems of the negative impact of oil and gas facilities on the environment Northern territories this necessitates the development of measures for the greening of land use based on the results of an environmental impact assessment and decision-making to minimize or eliminate them. The article presents the results of the environmental impact assessment of oil and gas facilities, zoning is conducted by the degree of impact and criteria for the degree of impact are defined. The results of the environmental impact assessment made it possible to assess the degree of anthropogenic impact of the study object and to develop recommendations for reducing adverse industrial effects in order to protect the environment.
\end{abstract}

\section{Introduction}

With the growth of energy consumption, the extraction of hydrocarbons and the number of developed fields increase, which leads to an increased anthropogenic impact on the environment. The development, construction, and exploitation of deposits cause changes in the natural landscape, accompanied by pollution of the adjacent territories, degradation of the soil cover, disturbance of the water regime, and destruction of vegetation. The anthropogenic impact on the environment leads to severe environmental effects at the ecosystem, biosphere and population-species levels. Due to the presence of huge hydrocarbon reserves, harsh climatic conditions, and, as a result, slow natural recovery processes, the Northern territories of the Russian Federation were more susceptible to the man-made impact from oil and gas facilities.

Scientific research and practice have shown that one of the tools for preventing and minimizing damage from oil and gas facilities is the environmental impact assessment procedure, as a process aimed at the timely identification of potential problems for further assessment of economic feasibility and the degree of environmental impact, as an activity for identifying, analyzing and accounting for direct and indirect effects of the environmental impact.

Environmental impact assessment is aimed at providing environmentally sound solutions to minimize adverse technogenic consequences from oil and gas production

\footnotetext{
${ }^{*}$ Corresponding author: giljovaln@tyuiu.ru
} 
facilities and minimize environmental and economic risks, which are a probabilistic measure of adverse changes in the ecosystem caused by human economic activity or the development of unsafe natural processes $[1,2]$.

The purpose of our study is to determine the degree of impact of oil production facilities on natural complexes during the operation of oil and gas fields and to establish zones by the degree of impact. And since it is easier to prevent than eliminate the environmental consequences of anthropogenic impact, the environmental impact assessment aimed at ensuring environmentally sound decisions to minimize adverse technogenic consequences from oil and gas facilities for making decisions to ensure environmental safety of the environment becomes particularly relevant in this regard.

\section{Materials and methods}

Object of research, «Arrangement of the Tazovsky field. Oil well cluster №7B, located in the Tazovsky district of the Yamal-Nenets Autonomous Okrug. Tazovsky district has significant reserves of oil and gas, which is produced at 10 major oil and gas fields. Operation of the Bush of oil wells №7B, as an object of the oil and gas complex (OGC) of the Tazovsky field, is planned in the gushing mode. To collect products, it is planned to use a mobile well development complex designed for the development and research of wells with abnormally high reservoir pressure, for which there is no system of oil collectors. The land area of the oil bush wells №7 is 15.63 ha.

In this research, the results of ecological and geological surveys in the territory of the study object were used as study materials, Atlas of the Yamalo-Nenets Autonomous Okrug, cartographic materials.

Abstract-logical, forecasting, cartographic, computational-constructive, analytical, statistical research methods, the method of analysis and synthesis were used.

The location of the Tazovsky field is characterized by severe climatic conditions: the absolute temperature minimum is $52.6^{\circ} \mathrm{C}$, the average of the absolute minima is $46.9^{\circ} \mathrm{C}$, and the average number of days with a stable snow cover is 232 days. The study area is located in the zone of tundra gley soils and sub-bores of the subarctic and is represented by peat swamp, tundra illuvial-humus and tundra gley soils. The vegetation cover of the area where the object is located is represented by ernikovye and willow-ernikovye shrub-lichenmoss tundras and flat-edged grass-moss-lichen swamps. Harsh climatic conditions contribute to the slow recovery of ecosystems, «vulnerability» Northern nature, which calls for a timely assessment of the impact of oil and gas facilities on natural landscapes of the Northern territories, as well as assessment of environmental and economic risks prevention and early warning from storage and transportation of oil and gas [3].

In terms of methodology, EIA is carried out in three stages in Table 1 [4].

Table 1. The methodology of zoning of the area affected.

\begin{tabular}{|c|c|}
\hline $\begin{array}{c}\text { Name of the } \\
\text { stage }\end{array}$ & Maintenance stage \\
\hline $\begin{array}{c}\text { The first } \\
\text { preliminary) } \\
\text { stage }\end{array}$ & $\begin{array}{c}\text { is meant for collecting, compiling and analyzing information on the } \\
\text { impact of the proposed anthropogenic activity on the natural environment } \\
\text { according to the available literature and archive materials. }\end{array}$ \\
\hline
\end{tabular}




\begin{tabular}{|c|c|}
\hline $\begin{array}{c}\text { The second } \\
\text { (assessment) } \\
\text { stage }\end{array}$ & $\begin{array}{c}\text { is meant to clarify the materials of the preliminary assessment and to form the } \\
\text { materials on EIA of the objects to be placed in the environment, development } \\
\text { of proposals for the program of industrial environmental monitoring and } \\
\text { control of the implementation of activities for the extraction of hydrocarbon } \\
\text { raw materials. }\end{array}$ \\
\hline $\begin{array}{c}\text { The third (final) } \\
\text { stage }\end{array}$ & $\begin{array}{c}\text { is meant to prepare the final version of the materials on EIA, taking into } \\
\text { account the compliance with comments to the preliminary version of the } \\
\text { materials. }\end{array}$ \\
\hline
\end{tabular}

The EIA is aimed at developing measures that can anticipate the development of degradation processes, which helps to predict the consequences of anthropogenic impact on the environment as a whole and on its individual components, which is the main result of its implementation.

\section{Results}

As a result of the study object environment condition literature and archive materials analysis and the preliminary EIA materials clarification, the main types of anthropogenic impacts on the study object within the boundaries of the sanitary protection zone were identified: 1) impact on the soil cover; 2) impact on water bodies; 3) impact on atmospheric air.

The zones of the study object environmental impact are presented in Fig. 1.

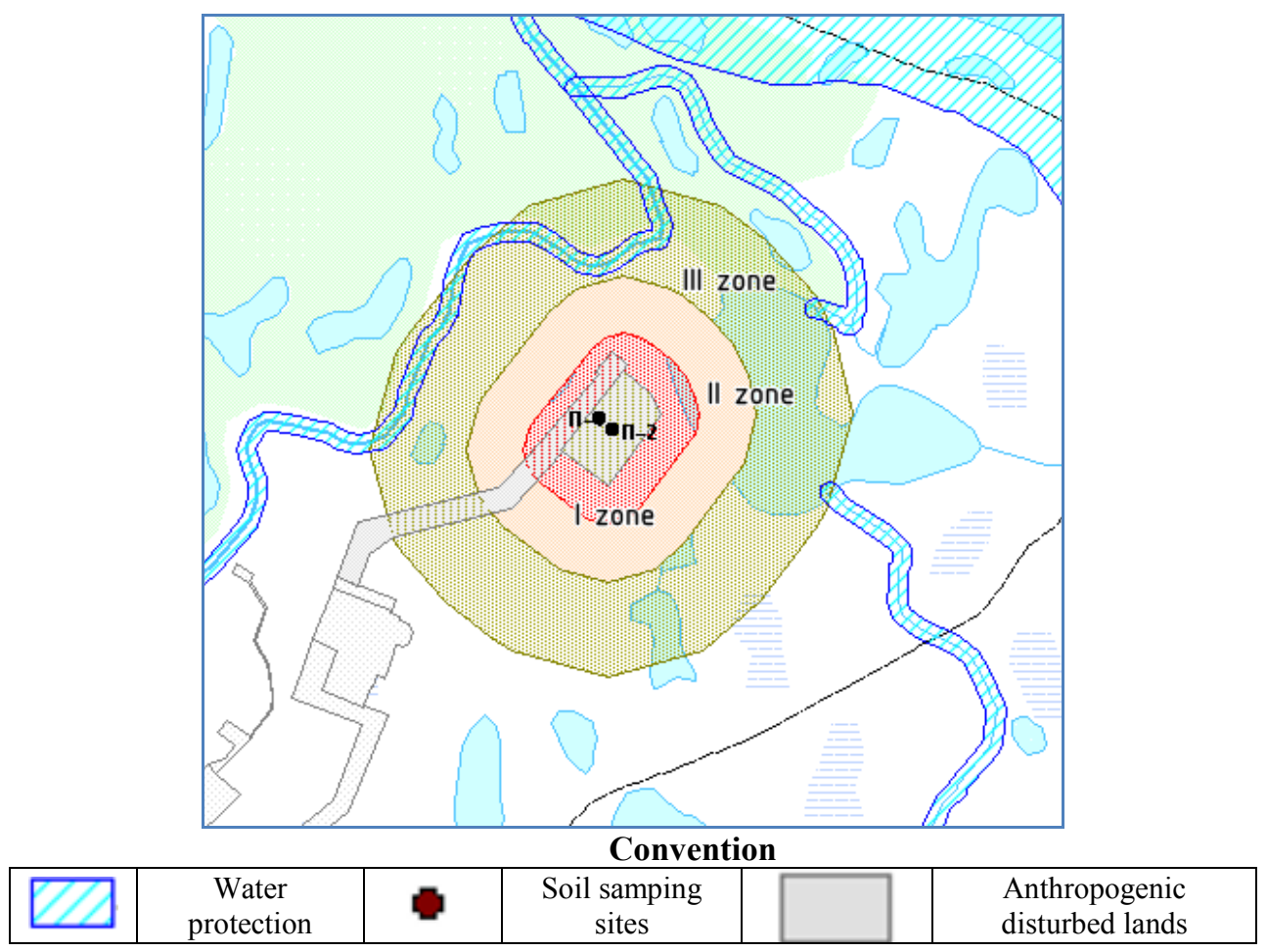

Fig. 1. Zoning of the object's impact area.

Zones areas and radii according to the degree of impact on the study object are presented in Table 2. 
Table 2. Zones areas according to the degree of impact of the study object.

\begin{tabular}{|c|c|c|c|c|}
\hline \multirow{2}{*}{ Impact zone } & \multirow{2}{*}{ Degree of impact } & Radius of the & \multicolumn{2}{|c|}{ Zone area } \\
\cline { 4 - 5 } & & {$[\mathrm{m}]$} & {$[\mathrm{ha}]$} & {$[\%]$} \\
\hline I zone of high impact & Strong & $500-1000$ & 44,35 & 13,7 \\
\hline II zone of average impact & Average & $200-500$ & 67,64 & 20,9 \\
\hline III zone of low impact & Weak & $0-200$ & 211,41 & 65,4 \\
\hline
\end{tabular}

Zones by the degree of impact of the object under study on the surrounding area are more clearly represented in the form of a graph in figure 2 .

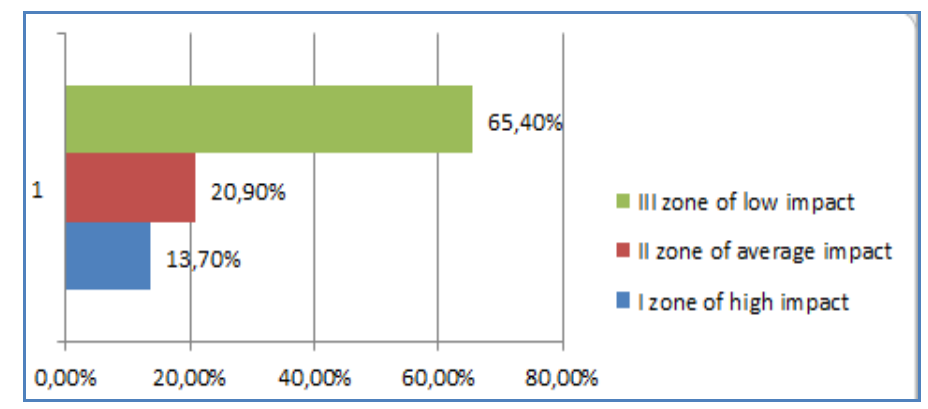

Fig. 2. Graphical representation of the impact of the object on the surrounding area, (\%).

The study object environmental impact criteria are set (Table 3 ).

Table 3. The study object environmental impact criteria.

\begin{tabular}{|c|c|}
\hline $\begin{array}{c}\text { Degree } \\
\text { of impact }\end{array}$ & Impact description \\
\hline Weak & $\begin{array}{l}\text { - impact on the soil cover: mechanical damage of soil, the chemical impact is not } \\
\text { detected or is below the MPC standards; } \\
\text { - impact on water bodies: no derangement of surface or underground runoff; } \\
\text { - impact on atmospheric air: insignificant, below the MPC standards }\end{array}$ \\
\hline Average & $\begin{array}{c}\text { - impact on the soil cover: mechanical damage or destruction of soil, chemical } \\
\text { impact within the limits of the MPC; } \\
\text { - impact on water bodies: flooding of the territory is indicated; } \\
\text { - impact on atmospheric air: within the limits of maximum permissible } \\
\text { concentration }\end{array}$ \\
\hline Strong & $\begin{array}{c}\text { - impact on the soil cover: derangement of the properties and structural damage of } \\
\text { soil cover (including moss cover), reduction of snow cover thickness, chemical } \\
\text { impact - exceeds the MPC standards; } \\
\text { - impact on water bodies: changes in the chemical composition of surface and } \\
\text { subsoil water; } \\
\text { - impact on atmospheric air: the thawing effect of wells, changes in snow } \\
\text { accumulation conditions, exceeds the MPC standards }\end{array}$ \\
\hline
\end{tabular}

At the final third stage, materials are prepared and an EIA report is generated.

One of the main objects of ecological and geochemical research is soil. Unlike water and atmospheric air, which are only migratory media, soil is the most objective and stable indicator of man-made pollution, it clearly reflects the distribution of pollutants and their actual distribution in the components of the natural environment [5].

To assess the impact, soil samples were selected and examined by an accredited testing laboratory center. 
A special place among the manifestations of anthropogenic impact on soils belongs to heavy metal pollution, since rapid self-cleaning of soils from metal pollution to the required level corresponding to hygienic and environmental safety is difficult, and in many cases almost impossible. As a result of the analysis of the impact assessment on the soil cover, it was found that the concentration of petroleum products is $50-250 \mathrm{mg} / \mathrm{kg}$, which is significantly lower than the background value $(100 \mathrm{mg} / \mathrm{kg})$. The concentration of heavy metals (lead, zinc, mercury) in the studied soils is below the established MPC and UEC. No exceedances of the MPC for all components were recorded.

Analysis of the surface water impact assessment showed that the concentration of most pollutants in the Yurkharovo River that flows to the east of the study object does not exceed the MPC standards, with the exception of zinc exceeding them by 2.0 times, copper - by 1.5 times and manganese - by 2.5 times. The increased content of these substances in surface waters is typical for the region. The content of petroleum products is below the existing MPC. The analysis of the data presented by the Federal service for Hydrometeorology and environmental monitoring «Yamalo-Nenets center for Hydrometeorology and environmental monitoring» has been established that to assess the impact on atmospheric air by the degree of air pollution on the excess over the results of the measurements of the content of harmful components over the MPC given hazard class. The analysis of the presented materials indicates that the MPC does not exceed the norms of atmospheric air pollution within the study area.

To ensure the environmental safety of the environment, scientists and practitioners suggest managing the natural resources of the Northern territories with the involvement of indigenous peoples living in this territory, conducting environmental management and industrial monitoring of anthropogenic disturbed lands $[6,7,8]$. The rational organization of the territory of deer pastures is particularly important for the indigenous peoples of the North, who are engaged in traditional economic activities $[9,10]$.

\section{Conclusions}

Using the evaluation criteria and zoning results, we can conclude that the object of the study is «Development of the Tazovsky field. Oil well cluster №7B» has an average impact on the environment. To reduce adverse man-made impacts on the environment during the operation of the facility, it is necessary to conduct industrial environmental monitoring, which provides for monitoring the state of components of the natural environment in the immediate vicinity of infrastructure facilities and will allow monitoring changes in the environment under the influence of anthropogenic factors before the start of construction and then annually during operation.

Recommendations for reducing adverse technogenic effects on the main components of the natural environment are presented in table 4.

Table 4. Recommendations for reducing adverse technological consequences.

\begin{tabular}{|c|c|}
\hline Name & Recommendations for reducing adverse technological consequences \\
\hline $\begin{array}{c}\text { Measures to prevent } \\
\text { soil pollution }\end{array}$ & $\begin{array}{c}\text { - movement of equipment within the boundaries of the land allotment; } \\
\text { - collapse of the site of well bushes, Parking of equipment, storage of fuel; } \\
\text { - organized collection of storage and disposal of industrial and household } \\
\text { waste, spent fuel products, prevention of unauthorized discharge of } \\
\text { petroleum products. }\end{array}$ \\
\hline $\begin{array}{c}\text { Measures to reduce } \\
\text { emissions of } \\
\text { pollutants into the } \\
\text { atmosphere }\end{array}$ & - timely inspection and maintenance of machinery and equipment; \\
- use of a cleaner type of fuel (diesel, gas)
\end{tabular}




\begin{tabular}{|c|c|}
\hline $\begin{array}{c}\text { Measures to reduce } \\
\text { the impact on } \\
\text { vegetation cover }\end{array}$ & $\begin{array}{r}\text { - carrying out works at stable negative temperatures and sufficient snow } \\
\text { cover to avoid additional disturbance of vegetation cover; }\end{array}$ \\
$\begin{array}{r}\text { - exclusion of traffic outside the designated and equipped areas and roads } \\
\text { to avoid mechanical impact on the landscape; }\end{array}$ \\
$\begin{array}{r}\text { - protection of the territory from flooding by ground and surface waters, } \\
\text { creation of drainage devices. }\end{array}$
\end{tabular}

Performed impact assessment of the oil and gas complex object «Development of the Tazovsky field. Oil well development №7B» on the environment will allow timely identification of the impact of negative processes associated with the production of hydrocarbon raw materials and to plan measures to reduce it in the territories of traditional nature management.

\section{References}

1. S.J., Pollard, UNESCO Encyclopedia of Life Support Systems, 219 - 235 (2002)

2. G.W. Suter II, Integrated Environmental Assessment and Management, 285-289 (2008)

3. Tianteng Wang, Tong Li, Yingzhi Xia, Zexi Zhang, Shikai Jin, Procedia Computer Science (2019)

4. L. Gileva, N. Egorova, Oil and Gas Studies, 1, 121-132 (2019) doi:10.31660/04450108-2019-1-121-132

5. E. H Winfried, Blum, Soil indicators for decision making - sharing knowledge between science, stakeholders and politics, 234 (2002)

6. O. Boiral, I. Heras-Saizarbitoria, M-C. Brotherton, Environmental Science \& Policy, 10-20 (2020)

7. N-M. Todaro, F.Testa, T. Daddi, F.Iraldo, Journal of Environmental Management Volume (2019)

8. J. Wang, T. Aenis, Journal of Environmental Management, 2431, 1-11 (2019)

9. L. Gileva, Belgorod State University Scientific Bulletin, 42, 435-445 (2018) doi:10.18413/2075-4671-2018-42-3-435-445

10. M. Podkovyrova, N. Ivanova, Agricultural Economics of Russia, 11, 80-86 (2019) doi: $10.32651 / 1911-80$

11. D. Gura, Y. Dubenko, E. Dyshkant, A. Pavlyukova, G. Akopyan, IOP Conference Series: Earth and Environmental Science 403(1), 012184 (2019). DOI: 10.1088/1755$1315 / 403 / 1 / 012184$

12. D.A. Gura, I.G. Markovskii, B.A. Hahuk, S.K. Pshidatok, IOP Conference Series: Materials Science and Engineering 698(4), 044014 (2019). DOI: 10.1088/1757899X/698/4/044014 